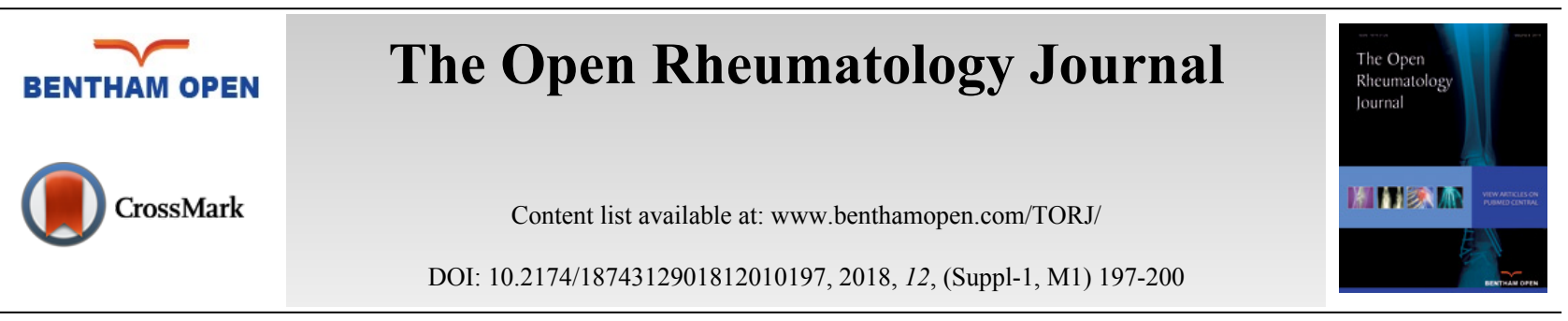

EDITORIAL

\title{
The Enigma of Vitamin D Role in Inflammation
}

Vitamin D is a widely studied molecule, but several aspects of its biologic behaviour remain unclear. Despite having been considered for decades solely as a co-actor of the bone metabolism regulation, multiple experimental observations have suggested a role in different fields of human physiology [1]. Notably, numerous authors attributed to vitamin D key functions in the regulation of the immune system [2 - 12], hence revealing its potential contribution in the management of inflammatory diseases [13 - 22].

However, as well as for other promising molecules under investigation, a significant gap between the strength of the in vitro data and the weakness of the in vivo observations still exists. There are several reasons beyond this discrepancy: for instance, experimental conditions in vitro cannot replicate the complex regulation of the vitamin D-dependent pathways in vivo; moreover, vitamin $\mathrm{D}$ concentrations used in vitro are generally significantly higher than those physiologically measured in human subjects. To date, the real and actual impact of the vitamin $\mathrm{D}$ status on inflammation in vivo is still an enigma. Consequently, whether or not vitamin D plays a relevant role in the development and management of inflammatory diseases is still a matter of debate. If, on the one side, we should not neglect vitamin D potentialities, on the other side, we must avoid considering it a "panacea", as this misinterpretation might lead to overtreatment with direct and indirect relevant costs [23, 24].

A large-scale screening and supplementation strategies for therapeutic indications other than the maintenance of bone homeostasis are currently not supported by the available evidence, and their clinical advantage and costeffectiveness are doubtful.

In this special issue, contributions from eminent figures in this field have been gathered to try to elucidate what we already know and what is new about vitamin $\mathrm{D}$ and inflammation.

At first, Trombetta and colleagues [25] extensively and comprehensively revised the current knowledge about the in vivo and in vitro vitamin $\mathrm{D}$ activity on the immune system regulation and its implications for the development of autoimmune diseases. To deepen the insights on specific pathological conditions, Nerviani et al. [26] reviewed the relevant literature about the impact of the vitamin D status on the clinical course of Systemic Lupus Erythematosus (SLE). In this manuscript, the authors presented the available data assessing the effects of vitamin D on several markers of disease activity, further discussing the evidence supporting a role for vitamin D supplementation in the management of SLE. The specific relationship with the antiphospholipid antibody syndrome has been revised in depth by Gualtierotti and colleagues [27], who also included original data showing the in vitro effects of vitamin D supplementation on the endothelial perturbation in this condition.

In the context of inflammatory arthritis, Crotti and colleagues [28] discussed the current evidence about the role of vitamin D in the development of spondyloarthritis; here the authors not only underpinned the discrepancies existing in this field, but also stressed the relevance that vitamin D status seems to have in the occurrence of some critical comorbidities in the course of systemic inflammatory diseases.

Resulting from the impairment of several biological pathways involved in the bone metabolism, osteoporosis and increased risk of fracture are common in inflammatory arthritis. Bone health and immune system are strictly related, and their complex and intriguing connections are the matter of study of a recently developed field known as "osteoimmunology". In this regards, Sainaghi and Gibbin [29] reviewed the available pieces of evidence supporting the direct implication of the vitamin D status in the development of osteoporosis in patients affected by inflammatory arthritis. 
Furthermore, cardiovascular diseases are classical and severe complications of chronic inflammatory disorders, widely accounting for the increased mortality observed in these conditions. The atherogenic profile related to the chronic inflammatory state largely contributes to the increased cardiovascular risk; nevertheless, as broadly discussed by Bellan and Marzullo [30] in their manuscript here enclosed, vitamin D seems to play a critical role in the regulation of the glucose metabolism, which is a primary determinant of the cardiovascular risk. If this link is generally valid in patients affected by Type 2 Diabetes, vitamin D appears to be even more relevant in Type 1 Diabetes, in which the aberrant activity of the immune system is essential. The impact of vitamin D status on Type I Diabetes development and management has been discussed here by Savastio et al. [31]. Finally, original data about the influence of the antiviral treatment on the vitamin D/parathyroid hormone axis in chronic hepatitis $\mathrm{C}$ have been here presented in the manuscript by Salmi et al. [32].

\section{REFERENCES}

[1] Gil Á, Plaza-Diaz J, Mesa MD. Vitamin D: Classic and novel actions. Ann Nutr Metab 2018; 72(2): 87-95. [http://dx.doi.org/10.1159/000486536] [PMID: 29346788]

[2] Bikle DD. Vitamin D and the immune system: role in protection against bacterial infection. Curr Opin Nephrol Hypertens 2008; 17(4): 348-52. [http://dx.doi.org/10.1097/MNH.0b013e3282ff64a3] [PMID: 18660668]

[3] Xu H, Soruri A, Gieseler RKH, Peters JH. 1,25-Dihydroxyvitamin D3 exerts opposing effects to IL-4 on MHC class-II antigen expression, accessory activity, and phagocytosis of human monocytes. Scand J Immunol 1993; 38(6): 535-40. [http://dx.doi.org/10.1111/j.1365-3083.1993.tb03237.x] [PMID: 8256111]

[4] Zhang Y, Leung DY, Richers BN, et al. Vitamin D inhibits monocyte/macrophage proinflammatory cytokine production by targeting MAPK phosphatase-1. J Immunol 2012; 188(5): 2127-35. [http://dx.doi.org/10.4049/jimmunol.1102412] [PMID: 22301548]

[5] Piemonti L, Monti P, Sironi M, et al. Vitamin D3 affects differentiation, maturation, and function of human monocyte-derived dendritic cells. J Immunol 2000; 164(9): 4443-51. [http://dx.doi.org/10.4049/jimmunol.164.9.4443] [PMID: 10779743]

[6] Griffin MD, Lutz WH, Phan VA, Bachman LA, McKean DJ, Kumar R. Potent inhibition of dendritic cell differentiation and maturation by vitamin D analogs. Biochem Biophys Res Commun 2000; 270(3): 701-8. [http://dx.doi.org/10.1006/bbrc.2000.2490] [PMID: 10772887]

[7] Gauzzi MC, Purificato C, Donato K, et al. Suppressive effect of 1alpha,25-dihydroxyvitamin D3 on type I IFN-mediated monocyte differentiation into dendritic cells: Impairment of functional activities and chemotaxis. J Immunol 2005; 174(1): 270-6. [http://dx.doi.org/10.4049/jimmunol.174.1.270] [PMID: 15611249]

[8] Chen S, Sims GP, Chen XX, Gu YY, Chen S, Lipsky PE. Modulatory effects of 1,25-dihydroxyvitamin D3 on human B cell differentiation. J Immunol 2007; 179(3): 1634-47.

[http://dx.doi.org/10.4049/jimmunol.179.3.1634] [PMID: 17641030]

[9] Cippitelli M, Fionda C, Di Bona D, et al. Negative regulation of CD95 ligand gene expression by vitamin D3 in T lymphocytes. J Immunol 2002; 168(3): 1154-66.

[http://dx.doi.org/10.4049/jimmunol.168.3.1154] [PMID: 11801650]

[10] Sloka S, Silva C, Wang J, Yong VW. Predominance of Th2 polarization by vitamin D through a STAT6-dependent mechanism. J Neuroinflammation 2011; 8: 56. [http://dx.doi.org/10.1186/1742-2094-8-56] [PMID: 21605467]

[11] Fasching P, Stradner M, Graninger W, Dejaco C, Fessler J. Therapeutic potential of targeting the Th17/Treg axis in autoimmune disorders. Molecules 2017; 22(1): E134.

[http://dx.doi.org/10.3390/molecules22010134] [PMID: 28098832]

[12] Zhang H, Shih DQ, Zhang X. Mechanisms underlying effects of 1,25-Dihydroxyvitamin D3 on the Th17 cells. Eur J Microbiol Immunol (Bp) 2013; 3(4): 237-40.

[http://dx.doi.org/10.1556/EuJMI.3.2013.4.1] [PMID: 24294492]

[13] Merlino LA, Curtis J, Mikuls TR, Cerhan JR, Criswell LA, Saag KG. Vitamin D intake is inversely associated with rheumatoid arthritis: Results from the Iowa Women's Health Study. Arthritis Rheum 2004; 50(1): 72-7. [http://dx.doi.org/10.1002/art.11434] [PMID: 14730601]

[14] Sainaghi PP, Bellan M, Nerviani A, et al. Superiority of a high loading dose of cholecalciferol to correct hypovitaminosis d in patients with inflammatory/autoimmune rheumatic diseases. J Rheumatol 2013; 40(2): 166-72. [http://dx.doi.org/10.3899/jrheum.120536] [PMID: 23242183]

[15] Sainaghi PP, Bellan M, Carda S, et al. Hypovitaminosis D and response to cholecalciferol supplementation in patients with autoimmune and non-autoimmune rheumatic diseases. Rheumatol Int 2012; 32(11): 3365-72. [http://dx.doi.org/10.1007/s00296-011-2170-x] [PMID: 22045518] 
[16] Sainaghi PP, Bellan M, Antonini G, Bellomo G, Pirisi M. Unsuppressed parathyroid hormone in patients with autoimmune/inflammatory rheumatic diseases: implications for vitamin D supplementation. Rheumatology (Oxford) 2011; 50(12): $2290-6$. [http://dx.doi.org/10.1093/rheumatology/ker314] [PMID: 22019806]

[17] Pierrot-Deseilligny C, Souberbielle JC. Is hypovitaminosis D one of the environmental risk factors for multiple sclerosis? Brain 2010; 133(Pt 7): $1869-88$. [http://dx.doi.org/10.1093/brain/awq147] [PMID: 20584945]

[18] Smolders J, Hupperts R, Barkhof F, et al. Efficacy of vitamin D3 as add-on therapy in patients with relapsing-remitting multiple sclerosis receiving subcutaneous interferon $\beta$-1a: A Phase II, multicenter, double-blind, randomized, placebo-controlled trial. J Neurol Sci 2011; 311(1-2): 44-9. [http://dx.doi.org/10.1016/j.jns.2011.04.013] [PMID: 21620416]

[19] Buondonno I, Rovera G, Sassi F, et al. Vitamin D and immunomodulation in early rheumatoid arthritis: A randomized double-blind placebocontrolled study. PLoS One 2017; 12(6): e0178463.

[http://dx.doi.org/10.1371/journal.pone.0178463] [PMID: 28582403]

[20] Bellan M, Sainaghi PP, Pirisi M. Role of Vitamin D in Rheumatoid Arthritis. Adv Exp Med Biol 2017; $996: 155-68$. [http://dx.doi.org/10.1007/978-3-319-56017-5_13] [PMID: 29124698]

[21] Bellan M, Pirisi M, Sainaghi PP. [Osteoporosis in Rheumatoid Arthritis: Role of the vitamin D/parathyroid hormone system]. Rev Bras Reumatol 2015; 55(3): 256-63.

[http://dx.doi.org/10.1016/j.rbr.2014.10.007] [PMID: 25582993]

[22] Chandrashekara S, Patted A. Role of vitamin D supplementation in improving disease activity in rheumatoid arthritis: An exploratory study. Int J Rheum Dis 2017; 20(7): 825-31.

[http://dx.doi.org/10.1111/1756-185X.12770] [PMID: 26481198]

[23] Glade MJ. Vitamin D: Health panacea or false prophet? Nutrition 2013; 29(1): 37-41. [http://dx.doi.org/10.1016/j.nut.2012.05.010] [PMID: 23085014]

[24] Cianferotti L, Bertoldo F, Bischoff-Ferrari HA, et al. Vitamin D supplementation in the prevention and management of major chronic diseases not related to mineral homeostasis in adults: Research for evidence and a scientific statement from the European society for clinical and economic aspects of osteoporosis and osteoarthritis (ESCEO). Endocrine 2017; 56(2): 245-61. [http://dx.doi.org/10.1007/s12020-017-1290-9] [PMID: 28390010]

[25] Trombetta AC, Paolino S, Cutolo M. Vitamin d, inflammation and immunity: Review of literature and considerations on recent translational and clinical research developments The Open Rheumatol J 2018; 12: 201-13.

[26] Nerviani A, Mauro D, Gilio M, Grembiale RD, Lewis M. To supplement or not to supplement? The rationale of vitamin D supplementation in systemic lupus erythematosus. The Open Rheumatol J 2018; 12: 214-25.

[27] Gualtierotti R, Di Giacomo A, Raschi E, Borghi MO, Meroni PL. Vitamin D and anti-phospholipid antibody syndrome. The Open Rheumatol J 2018; 12: 226-47.

[28] Crotti C, Becciolini A, Biggioggero M, Favalli EG. Vitamin D and spondyloarthritis: Review of the literature. The Open Rheumatol J 2018; 12: $248-60$.

[29] Sainaghi PP, Gibbin A. Vitamin D, inflammation and Osteoporosis in Rheumatoid Arthritis. The Open Rheumatol J 2018; 12 : 261-78.

[30] Bellan M, Marzullo P. New insights on low vitamin D plasma concentration as a potential cardiovascular risk factor. The Open Rheumatol J 2018; 12: 279-88.

[31] Savastio S, Cadario F, Beux S, et al. Vitamin D and type I diabetes. The Open Rheumatol J 2018; 12: $289-99$.

[32] Salmi L, Barbaglia MN, Bianco S, Guaschino G, Minisini R, Pirisi M. Detrimental impact of interferon-based regimens on vitamin D/parathyroid hormone homeostasis. The Open Rheumatol J 2018; 12: 300-12.

Mattia Bellan

Department of Translational Medicine Università del Piemonte Orientale UPO via Solaroli 17

Novara (NO), 28100

Italy

Tel: +390321-3733966

E-mail: bellanmattia@yahoo.it

Division of Internal Medicine

Sant'Andrea Hospital

Vercelli 
IRCAD

Interdisciplinary Research Center of Autoimmune Diseases

Novara

Italy

Alessandra Nerviani

Experimental Medicine and Rheumatology William Harvey Research Institute and Barts and The London School of Medicine and Dentistry

Queen Mary University of London

London

UK

IRCAD

Interdisciplinary Research Center of Autoimmune Diseases

Novara

Italy

Pier Paolo Sainaghi

Immuno-rheumatology Outpatien Unit AOU Maggiore della Carità

Novara

Italy

IRCAD

Interdisciplinary Research Center of Autoimmune Diseases

Novara

Italy

\section{(C) 2018 Bellan et al.}

This is an open access article distributed under the terms of the Creative Commons Attribution 4.0 International Public License (CC-BY 4.0), a copy of which is available at: (https://creativecommons.org/licenses/by/4.0/legalcode). This license permits unrestricted use, distribution, and reproduction in any medium, provided the original author and source are credited. 